\title{
ФУНКЦИОНИРОВАНИЕ МЕСТОИМЕНИЙ В ИСПАНСКОМ ЯЗЫКЕ НА ТЕРРИТОРИИ МЕКСИКАНСКОГО ШТАТА ОАХАКА
}

\section{THE FUNCTIONING OF SPANISH PRONOUNS IN THE TERRITORY OF THE MEXICAN STATE OF OAXACA}

I. Smirnova

S. Clemente-Smirnova

Summary: The article discusses the use of pronouns in the state of 0axaca. A hypothesis is put forward about the possible influence of Indian languages on the formation of locally specific features of Oaxacan speech. Examples of the functioning of pronouns in Spanish in this region are given. The analysis of the Oaxaca speech is based on a survey of residents of Oaxaca, a study of literature and articles from the Internet. The article concludes that it is necessary to continue research on the possible influence of Indian languages on the Spanish language in the region.

Keywords: Spanish, pronouns, features, Indian languages, Mexico, 0ахаса.

\author{
Смирнова Ирина Викторовна \\ Дочент, Российский университет дружбы народов \\ (2. Москва) \\ nomeolvides333@yandex.ru \\ Клементе-Смирнова Светлана Донатовна \\ Аспирант, Российский университет дружбы народов \\ (2. Москва) \\ ksdsvetik@yandex.ru
}

Аннотация: В статье рассматривается употребление местоимений в штате Оахака. Выдвигается гипотеза о возможном влиянии индейских языков на формирование локально-специфических особенностей речи оахакцев. Приводятся примеры функционирования местоимений в испанском языке в данном регионе. Анализ оахакской речи проводится на основе опроса жителей штата Оахака, изучения литературы и статей из сети Интернет. В статье делается вывод о необходимости продолжения исследования возможного влияния индейских языков на испанский язык в регионе.

Ключевые слова: испанский язык, местоимения, особенности, индейские языки, Мексика, штат Оахака.

- Nosotros trabajamos duro para salvar la tortuga. Nosotros recolectamos huevos... «Мы усердно работаем, чтобы спасти черепах. Мы собираем яйца...» (запись)

- Si tú quieres, vamos a comer estas tunas porque están muy dulces. «Если хочешь, съедим эти туны, потому что они очень сладкие». [8.с.22]

- Andrés Huesca, aquel compositor veracruzano, autor de "Tres días sin verte, mujer" y "Aún se acuerda de mí", entre otras canciones. Huesca murió ahogado en el Papaloapan debido a que él andaba ahogado de alcohol. «Андрес Уэска, композитор из Веракруса, автор таких песен как «Три дня без тебя, женщина» и «Все еще помнит меня». Уэска умер, утонув в Папалоапане, потому что много пил». [2. с.2]

La tierra es la madre de todos, es ella quien nos da el agua y los alimentos para vivir. «Земля - наша мать, она дает нам воду и пищу, чтобы жить». [1. с.16]

Отличительной чертой оахакской речи является употребление личного местоимения, как перед глаголом, так и после него. Приведем несколько примеров:

- ... En una fiesta andaba yo. «Я была на празднике». (запись)

- Mira, como lo hago yo. «Смотри, как я это делаю». (запись)

Анализируя речь жителей штата, было отмечено, что оахакцы употребляют беспредложную форму местоимения в дательном падеже не только относительно лица, 
но и предмета. Например:

- Al horno se le hecha la leña. “В печь подбрасывают дрова». (запись)

- A estas palabras o partículas se les conoce como adjetivos. «Эти слова или частицы известны, как прилагательные». [3. с.25]

- Para esto, se usa un recipiente de barro, un plato, por ejemplo, se pone carbón se le prende fuego y se echan a la lumbre un puñado de chiles secos. «Для этого используется глиняная емкость, тарелка, например, на нее кладут древесный уголь, его поджигают и бросают в огонь горсть сушеного перца чили». [1, с.27]

В письменной и в устной речи местоимения в дательном и в винительном падежах могут употребляться в разных родах и числах относительно одного и того же объекта:

- El coco yo Ia ocupo para la casa. «Кокос я использую в доме». (запись)

- Nos gusta y te agrada a todo este relajo. «Нам нравится и всем нравится такой отдых». (запись)

- El Ti'va es astuta y muy inteligente, muchas personas al oír su canto la corretean, le avientan piedras e intentan matarla. «Эль-Тива хитрая и очень умная, эта птица очень быстра и, когда чувствует опасность, быстро улетает». [1, с.27]

Наравне с безударными формами употребляются ударные формы местоимений с предлогом:

- No queremos esto para nosotros... «Мы не хотим этого для себя ...» (запись)

- La lengua nos define. Con ella explicamos, nombramos, damos dimensión, habitamos el mundo. Gracias a ella la humanidad ha establecido una forma de comunicación entre sus miembros. «Язык определяет нас. Через него мы объясняем, называем, даем определение, познаем мир. Благодаря ему человечество общается между собой». [5, с.1]

- Somos sus hijos, en ella vivimos. Ella nos vio nacer, nos ve crecer y nos verá morir. «Мы ее дети. Мы живем на ней. Она видела, как мы родились, как мы растем, и увидит, как мы умрем». [1, с.16]

- ... con ello surgió la discriminación, al haber una lengua única en los servicios del estado: educación, salud, oficinas de gobierno, en los medios de difusión, etcétera. «В связи С этим возникла дискриминация, поскольку существовал единый язык в государственных услугах: образование, здравоохранение, государственные учреждения, средства массовой информации и т.д.» $[4$, с.2]

Также было выявлено, что в речи оахакцев частотность употребления местоименных глаголов выше, чем среди жителей Мехико. Глаголы с местоимением -se употребляются всегда, когда действие направлено на лицо или предмет:

- Pero el coyote no sabía que esta tuna no estaba pelada. La tuna tenía las espinas todavía, y se la tragó entera, con todo y espinas. «Койот не знал, что на этот раз туна не была очищена. Туна была с колючками. Он проглотил ее целиком вместе с колючками». [8, с. 22]

- El conejo tomó la tuna que había pelado y se la metió en la boca al coyote. «Кролик взял очищенную туну и бросил ее в рот койота». [8, с. 22]

- Si te acercas, te arde la nariz, la garganta y te chillan los ojos. «Если ты подойдешь ближе, тебе будет жечь нос и горло, и начнут слезиться глаза». [1, с. 22]

Местоименные глаголы чаще употребляются в неопределенно-личном значении в 3 лице единственного числа c -sе вместо 3 лица множественного числа:

- Se le dio el nombre de Kokuví ya que el sonido que emite en su canto suena así: kokuví-kokuví-kokuví. «Ей дали название Кокуви так как крик, который она издает звучит, как кокуви-кокуви-кокуви». [1, с. 22]

-El mixteco usado en el presente libro es el que se habla en San Esteban Atatláhuca, Tlaxiaco, Оахаса. «В этой книге мы используемый миштекский язык, на котором говорят в Сан-Эстебане Ататлахука, Тлашьако, Оахака». [8, с. 5]

Вместо артикля чаще всего оахакцы употребляют притяжательные местоимения. Следует отметить, что притяжательные местоимения также как и беспредложные относятся не только к лицу, но и предмету, например: реке, животному, дому, прибору.

- Aquí viene su tomatito y su chilito... «Вот тут ваш помидорчик и ваш перчик». (запись)

-Y pues, através de mis hermanos surgió la idea... «Итак, у меня с братьями возникла идея...» (запись)

- En los pueblos mixtecos de Santa María Yucuhiti, vive en sus bosques y montes una pequeña ave nombrada por los nativos como Kokuví . «В миштекских деревнях СантаМария-Юкухити в лесах живет небольшая птичка, которую местные жители назвали Кокуви». [1.с 22]

- Gracias porque sembraron en mí el amor y el respeto por mi lengua, por mi gente, por mis tradiciones y por mis valores. «Спасибо за то, что привили мне любовь и уважение к моему языку, моему народу, моим традициям и моим ценностям». [1.с 1]

- Por ejemplo: yo hablo español, es mi lengua materna, pero $\boldsymbol{m i}$ dialecto, $\boldsymbol{m i}$ variante dialectal específica es el español mexicano del sur, específicamente el de la ciudad de Oaхаса. «Например, я говорю по-испански, это мой родной язык, но мой диалект, мой вариант - южный диалект мексиканского испанского, присущий Оахаке». [4.с 3]

- Que todo hay allí como aquí. Que igual tiene sus plantas y sus animales, sus hombres y sus mujeres. «Все, что там есть, есть здесь. Также есть свои растения и свои животные, свои мужчины и свои женщины». [7. с.1]

- Dicen, pues, nuestros ancianos que los antiguos dejaron dicho que cuando la gente muere es porque ya su anmajä'äwën (su alma, su fuerza, su energía) ha salido de su cuerpo. «Итак, наши старики говорят, что наши предки говорили, что люди умирают, когда их анмаджааван (их 
душа, их сила, их энергия) покинули их тело». [7. с.1]

Также вместо артикля могут употребляться указательные местоимения:

- Tomando en cuenta esta problemática, escribí estos textos en donde encontrarán breves narraciones que buscan retratar las creencias, las costumbres y los conocimientos propios (cosmovisión) de la región de Santa María Yucuhiti. «Принимая во внимание этот вопрос, я написал эти тексты, в которых вы найдете краткое описание, которое отображает верования, обычаи и собственное знание (космическое видение) региона Санта-Мария-Юкухити». $[1$, c. 4]

- Como se sabe, cuando un lengua ya no es usada por los niños y jóvenes esa lengua comienza el proceso de desaparición, algunas veces reversible pero en la mayoría de casos no. «Как известно, когда язык больше не используется детьми и молодежью, начинается процесс исчезновения данного языка, иногда этот процесс обратим, но в большинстве случаев - нет». [5, с. 1]

- Esta región colinda con los estados de Puebla y Guerrero, al este con la Cacada, al sureste con los Valles centrales y al sur con la Sierra sur. Esta región ocupa aproximadamente 189 municipios. Esta región cuenta con los platillos más ricos de Oaxaca, platillos que en su mayoría cuentan con el picante... «Этот регион граничит со штатами Пуэбла и Герреро, на востоке с Каньада, на юго-востоке с Центральными Долинами и на юге со Сьерра Сур. Этот регион охватывает около 189 муниципалитетов. В этом регионе самые вкусные блюда Оахаки. Блюда, которые в основном содержат перец...» [6. с.3, 4]

Следует отметить, что в речи сельских жителей отрицательное местоимение «никто» имеет форму «naiden», а местоимение «ничего» с предлогом «для» употребляется, как одно слово «ра'nа»:

- ... Ya hemos hecho varias solicitudes, pero naiden quiere darnos apoyos... «... Мы уже несколько раз делали запросы, но никто не хочет нам помочь...» (запись)

- ... Pa'na voy a afrentarse de mi color... «... Я вовсе не собираюсь стыдиться своего цвета кожи...» (запись)

В заключении, можно сделать вывод, что реализация местоимений в речи жителей Оахака характеризуется локально-специфическими особенностями. Специфика употребления местоимений в речи оахакцев могла быть сформирована под влиянием индейских языков. Данный вопрос требует более детального изучения.

\section{ЛИТЕРАТУРА}

1. Alcibíades López López. Relatos mixtecos de la región de Santa María Yucuhiti. Tlaxiaco. Oaxaca. Versión en español y mixteco Oaxaca. México: 2017, Pp.30.

2. Álvaro Estrada. Los duendes de la lengua. https://www.jornada.com.mx/1999/11/14/oja-duendes.html (дата обращения: 25.10.2020)

3. Carole Vanden Hoek de Jamieson. Gramática mazateco de San Pedro Amuzgos, Oax. Publicado por el Instituto Linguístico de Verano, A.C. México: 1988 , Pp.185.

4. Editor Digital. Oaxaca y sus regiones. //Режим доступа: http://exploraoaxaca.mx/7369/donde-ir/oaxaca-y-sus-regiones/ (дата обращения: 25.10.2020)

5. Juan Pablo Ruiz Nuñéz. Por la diversidad linguistica de México у Оахаса. //Режим доступа: http://www.eloriente.net/home/2014/03/20/por-la-diversidadlinguistica-de-mexico-y-оахаса (дата обращения: 25.10.2020)

6. Regiones de gastronomía nacional. UNID. //Режим доступа: https://moodle2.unid.edu.mx/dts_cursos_mdl/lic/AET/RGN/S11/RGN11_Lectura.pdf (дата 06ращения: 25.10.2020)

7. Reyes Gómez Juan Carlos. Muerte-vida-fin principio ayuuk. Tuk it ets ja tuk it. Este mundo, el otro mundo. //Режим доступа: https://www.jornada.com. mx/2006/01/16/oja105-juan.html (дата обращения: 25.10.2020)

8. Ruth Mary Alexander Cornelia Mak. El Mixteco Idioma de una Cultura Antigua. Con un Breve Vocabulario. Mixteco de San Esteban Atatláhuca. //Режим доступа: http://www.sil.org/mexico/mixteca/atatlahuca/L197-LeerMixteco-mib.htm (дата обращения: 25.10.2020)

9. Электронный ресурс. //Режим доступа: https://geosfera.org/severnaya-amerika/meksika/2393-oahaka.html 